\title{
ENSAYOS
}

\section{Poesía Crítica: Lenguaje y Silencio}

\author{
Cuando una sociedad se corrompe, lo. \\ primero que se gangrena es el. lenguaje. \\ Octavio PaZ \\ And, as the prestige of language falls. \\ that of silence rises.
}

SUSAN SONTAG

En un poema de los años cincuenta, al final, Borges oye una voz que le recuerda la vanidad de su ejercicio poético: "Has gastado los años y te han gastado, / Y todavia no has escrito el poema". Revelación de un fracaso personal o no, en esa frase se estaba aludiendo también a una: experiencia límite de la creación misma. "Nadie puede escribir un libro", dirá Borges después, de manera más concluyente y universal, en uno de esos nuevos poemas suyos aparentemente nada inquietantes. ¿A qué quie. re aludir con esta afirmación? Como Rilke, Borges parece creer en la creación como resultado de una profunda vivencia y una paciente comu-nión con las cosas; sólo de tal relación puede surgir el poema auténtico. Este sería como la cristalización de una sabiduría viva del universo. Asi, en el contexto del poema citado (para "Que un libro sea verdaderamente, / Se requieren la aurora y el poniente, / Siglos, armas y el mar que une y separa"), esa frase se refiere, obviamente, a la imposibilidad del escritor para traducir una experiencia total del mundo: éste es inagotable, aquélla es limitada. Pero sabemos que Borges no se detiene alli. Los grandes temas y el movimiento esencial de su poesía se inscriben dentro de un impulso no vertiginoso pero sí contradictorio: el no-ser es una forma más substancial de ser; la desposesión, una manera de posesión, la ausencia, otra presencia más profunda; el yo, una empresa de despersonalización; la literatura como juego que se desenmascara a sí mismo $y$, sin embargo (and yet, and yet), en ese juego va implicada una visión dramática del mundo. Toda su obra oscila entre el impulso hacia un absoluto poético (como Mallarmé, el libro que sea el Libro que, a su vez, sea: 
el Universo) y la no menos radical intuición de que ese impulso concluye siempre en el fracaso. No es el momento de repetir acá los análisis que ya se han hecho sobre esta tensión de la obra borgiana; bastaría con decir que esa obra es una paradoja: aspiración a la Obra y negación de ella, escritura que reescribe lo ya escrito y también lo desescribe, fidelidad y ruptura, pasión e ironía (¿humildad, orgullo?) frente al lenguaje. Esa paradoja funciona dentro de otras más. $\mathrm{La}$ aparente limitación encierra una empresa más desmesurada: hacer de la Obra el equivalente de Dios. En su último libro de poemas (Elogio de la sombra, 1969), Borges llega, al menos, a su secreto, pero la posesión del secreto lo remite igualmente al silencio; como uno de los personajes de sus relatos, quien ya tiene la última respuesta no puede decirla. Borges, de alguna manera, es ya el Otro.

A la imposibilidad - digamos, metafísica - de Borges, Octavio Paz añade otra que es también de orden estético, moral e histórico. Al poeta no le queda, dice en uno de sus últimos poemas, "Sino escribir comentarios / Insensatos / Sobre la ausencia de sentido del escribir"; añade: esos comentarios se bcrran además (Ladera Este, 1969). En un poema muy anterior, Paz había sido todavía más drástico: "no tengo nada que decir, nadie tiene nada que decir, nada / ni nadie excepto la sangre" ( $L a$ estación vialenta, 1958). Incluso hay todo un período de profunda crisis en su poesia, en que el discurso nunca parece culminar sino que se resuelve en continuos paréntesis, comentarios al margen, o en violentas antitesis, juegos verbales, profanaciones del significado; es decir, el discurso enfrentado a su propio vacío (Salamandra, 1962). Paz experimen. ta entonces, por una parte; la neutralidad del mundo; por la otra, el desgaste, el equivoco $\mathrm{y}$, más aún, la infeccion del lenguaje: las palabras no dicen lo que dicen y aun lo que dicen se desdice "del silencio al grito / desoído". Escribir se le vuelve una suerte de expiación. Respuesta a todo ello: la poesía debe ocultar sus poderes, olvidarse, regresar hacia sí misma, desmistificar al lenguaje en busca de la "roja palabra del principio", la palabra "antes de la caída". Así, lo que propone Paz es el silencio: "Inocencia y no ciencia / para hablar aprender a callar". Aunque este rasgo no agota toda su poesía (hay muchos Paz), es evidente que opera en ella, incluso desde sus comienzos, como la rasgadura de la lucidez. Esta lucidez es la revelación de una realidad precaria y su conciencia crítica. Aun la destellante plenitud (transparencia solar, mediodía en vilo) que alcanzan muchos de sus textos, está regida por esa conciencia de la desposesión y del desamparo aunque es válido, también, decir lo contraxio, de tal modo son términos que se polarizan entre sí. Para Paz, la poe. 
sía es siempre transgresión de un límite, aunque no deja de percibir su imposibilidad. Ya no se trata, como en Borges, de la imposibilidad del poema por ser el Poema, la de la escritura por alcanzar su absoluto y revelar así el sentido total del universo. $O$ de alguna manera se trata de lo mismo, sólo que con implicaciones y respuestas distintas. Lo que él afirma es el impase a que se ve enfrentada la nueva escritura poética: obliga. da a ser lenguaje, tiene que luchar contra él, despojarlo de sus rutinas, su ritual vacío, para librar luego su energía original. Pero además, marcado por la nostalgia de la tentativa de Rimbaud, la poesia se le presenta sobre todo como un impulso por cambiar la vida, por reconciliar la historia con el tiempo de la poesía: encarnación de la realidad, aunque sea por un instante. Esta exigencia extrema encierra, por supuesto, la desilusión. Después de Rimbaud, dice Paz en uno de sus ensayos, nadie escribe poesía sin un sentimiento de inutilidad. Este sentimiento no logra, sin embargo, erradicar la voluntad de transgresión. También para él, "la modernité commence avec la recherche d'une Littérature impossible", como dice Roland Barthes (Le degré zére de l'écriture, 1953). El propio Paz lo propone así en un ensayo: "la poesía moderna es una tentativa por abo. lir todas las significaciones porque ella misma se presiente como el significado último de la vida y del hombre". Ia poesía seria, entonces, el rescate del pensamiento utópico. Aun Paz prevé el renacimiento del arte "como acción y representación colectivas y el de su complemento contradictotio, la meditación solitaria" (Corriente alterna, 1967). Su último libro de poemas es ya el intento por identificarse con ese nuevo arte: trascender la historia en un Presente perpetuo, pacto de los contrarios, acceso a la limpidez y a lo absoluto en el mundo mismo ("Habito una transparencia", "Perfección de lo Finito"). Pero, cuidado, Paz no pretende fundar la poesía en un fácil optimismo; por el contrario, para llegar a la Palabra hay que recorrer el camino del silencio: el silencio como crítica y purificación. Así, a lo que él nos enfrenta es a una poesía crítica (toda creación auténtica lo es siempre). Y aunque él es uno de los que la asumen de manera más intensa en la nueva tradición latinoamericana, no es el único ejemplo ni su scla modalidad.

En uno de sus últimos libros (El sol ciego, 1966), Humberto Díaz Casanueva desarrolla una despiadada y casi tiránica reflexión sobre el mundo. Ese libro es una extensa elegía (no "elegíaca") a la muette de Rosamel del Valle, un poeta, como el propio Díaz Casanueva, de visiones órficas y, por ello mismo, del verdadero destierro en nuestra época. Pero esa elegía desborda la dimensión puramente individual; de alguna maneta es también la elegía a nuestro mundo, a nuestra historia, a nuestra au- 
sencia. Ese sol que se apaga, o mejor: ese "sol ciego / rodando al fondo de todos nosotros", no es tan sólo la imagen o el símbolo del poeta muerto; lo es igualmente de Ja conciencia del hombre actual y del ámbito en que vive. Asi, iluminado o ensombrecido (iluminado por la sombra de sur propia ruina), fragmentado, el mundo se afantasma y pierde sus significaciones. A lo cual corresponde una palabra que discurre en la incertidumbre o en la certidumbre de su inutilidad. "Nadie dice nada / porque nada tiene sentido", escribe Díaz Casanueva. Y de seguidas, con una visión alucinante pero precisa de lo que es el destino mismo, agrega: "Lo irrevocable / es una verdad vacía / que nos acecha / sin razón verdadera". ¿Cómo entonces encarar una realidad que se ha vuelto incoherente e irreal, o una fatalidad que sólo es designio brutal, que no comprendemos nunca? Queda, aparentemente, la poesía. Pero la poesía es sobre to do escritura, forma y ésta "nos libera de la nada / al mismo tiempo que a ella nos conduce". No hay, pues, más liberación que la lucidez de la condena; no hay más sentido que la contradicción. Sólo que esa lucidez no es un alto, sino un movimiento vertiginoso; impone una exigencia aún más insaciable: no sólo asumir la contradicción, sino extremarla a través de una escritura que sea también una metaescritura, un más allá del lenguaje. Por ello, finalmente, de la evocación de la tentativa creadora de Rosamel del Valle, el poeta pone de relieve esta lección: "Me enseñaste / a aborrecer el oficio / A desdeñar la tinta / A suprimir las vocales / A trabajar a pura sangre / desbocada". Se ve, la poesía no puede ser para Díaz Casanueva una consolación (como en cierta manera lo es para. Borges, aunque ya sabemos con qué sentido irónico), sino una suerte de ética de la desesperación. Incluso una blasfemia, a pesar, o por ello mismo, de la naturaleza sagrada que él le asigna. "Cuándo, cuándo he sido /. verdaderamente humano?" se pregunta en un poema de Los penitenciales (1960), del cual este libro es ahora la prolongación e intensificación.

Esa ética de la desesperación es también la experiencia esencial de poetas de otras generaciones. Es quizá el centro de una obra como la de Alberto Girri. Esa obra es, en efecto, un permanente movimiento en torno a un punto fijo y obsesivo: la visión de un mundo degradado y una conciencia que lo rechaza, abjura de él, lo juzga implacablemente. Pero esa cohciencia no actúa a distancia, sino sumergida en el mismo mundo que repudia, abismada en su seducción, viviendo de la caída perpetua, y así desviviéndose. De ahí un lenguaje que se funda en la ambivalencia del rigor. Aparentemente nace de la confianza y aun la fascinación: "inventada eternidad en la que todavía creo", dice Girri de la palabra, casi al comienzo de su trabajo poético (Playa sola, 1946). Esa confianza no ex- 
cluye sino que exige más bien la vigilancia, la lucidez crítica que va cada vez reduciendo la palabra a lo esencial, a un punto donde todo equívoco sea imposible. Ese punto es el cero ("porque en el cero no existe error", El ojo, 1964); es decir, el silencio, la desposesión del lenguaje, que corresponderia a una desposesión existencial. Pero el cero es también tao, el camino hacia otra plenitud y otra palabra (El ojo, 1964). La poesía de Girri es una reflexión intelectual y exacerbada sobre "el universo / entencido como cálculo y crispación" (Elegías italianas, 1962). En la de Eduardo Lozano (al menos en su último libro, De nacer y de morir, 1965) esa exacerbación es una fuerza profundamente emotiva; una fuerza soterrada, deșcarnada, más cercana a la inocencia, o en busca de ella. En esta poesía no hay juicio sino denuncia, secreta pero desgarrada: como en Vallejo, el sufrimiento mismo es un escándalo en el mundo. Sin embargo, la tensión interior de esta poesía no se resuelve sino en la palabra: transgresión continua ( $y$ no puramente instintiva) del lenguaje. Una sintaxis dislocada y aun violenta se combina con giros de un idioma deliberadamente arcaico y arcádico, que parece del alba misma del español (recuerda mucho al Cancionero medieval). Esta fusión sorprende, pero nos da sobre todo el sentido de una visión: crítica de la actualidad (hasta de una falsa modernidad), rescate de una plenitud más auténtica. La ética de la desesperación es, pues, una ética del lenguaje.

Dentro de más o menos igual perspectiva, Nicanor Parra aporta una visión más desquiciante. Para él, el mundo no sólo carece de sentido o lo ha perdido; es sobre todo absurdo. En todo absurdo hay una implicación trágica; Parra lo revela especialmente en su aspecto cómico y aun grotesco. Más que ningún otro poeta latinoamericano, es él quien ha introducido el humor negro. Ese humor puede suscitar la risa y hasta la carcajada, pero quien ríe no ignora que lo espera una angustia más secreta. El humor de Parra no produce una catarsis; la suspende, más bien, hasta que el lector descubra en él su propio espejo, su vacío. Parra no intenta trascender el absurdo; busca, por el contrario, hacerlo más acechante, intensificarlo, llevarlo incluso hasta la exasperación. Y el absurdo empieza a operar sobre el lenguaje mismo. No se trata tanto de distorsionarlo (la sintaxis de $\mathrm{Pa}$ ira no puede ser más nítida y elemental, irónicamente sentenciosa), o de desacralizarlo (aunque en este sentido sus métodos parezcan más eficaces). Se trata, creo, de un proceso más secreto: la reducción progresiva del lenguaje; mostrar, no sus antiguos poderes, sino su precariedad actual. Hay que hacer regresar la poesía a sus raices, propone Parra. Ese regreso es la búsqueda de la palabra desnuda: no sugerir, sino nombrar, decir; acortar la distancia entre las palabras y las cosas, hacer que éstas surjan sin me- 
diación alguna, como un impacto de la realidad (sólo que esta realidad es vista bajo la luz de una conciencia cuya vigilia es también pesadilla). Así, las palabras serían como gestos de las cosas y su prolongación; por ello mismo, quizá podrían desaparecer. No en vano para Parra el género supremo es la pantomima. Su lenguaje está al borde del silencio: un camino directo a la nada. Quiere aniquilar el lenguaje para que el mundo hable; reencontrar, de verdad, la palabra capaz de darle un nuevo sentido. ¿Nostalgia de la unidad? No es ella, sin embargo, la que priva en su obra, sino la voluntad de aniquilamiento, que se intensifica en sus textos más recientes y actúa como una fuerza ajena al autor. Este siente que el arte, la ciencia, el sexo "lo degeneran". Más allá de sus deseos, admite que "se terminó la inspiración". El lenguaje se le convierte en total desintegración: "Puedo decir palabras aisladas: / Arbol, árabe, sombra, tinta china, / Pero no puedo construir una frase" (sin embargo, qué bien escogidas están esas palabras aisladas). Experimenta, además, el desgaste, el cansancio de toda expresión: "Ya no me queda nada por decir / Todo lo que tenía que decir / $\mathrm{Ha}$ sido dicho no sé cuántas veces" (Versos de salón, 1962). Finalmente esa conciencia corrosiva se apodera de su propio discurso, lo desdice, lo repudia: "Me retracto de todo lo dicho. / Con toda la amargura del mundo. / Me retracto de todo lo que he dicho". Incluso se sabe que ya Parra no escribe sino artefactos: desmantelamiento (¿o explosión?) de la poesía, de su propia antipoesía, y aun del mun. do. "Ruido multiplicado por silencio".

No toda reducción del lenguaje surge del humor negro exacerbado hasta el absurdo. En Roberto Juarroz, esa reducción corresponde, con menos énfasis, a un debate más secreto, de orden ontológico (y ojalá el ad. jetivo pierda acá toda solemnidad y, más aún, la vaguedad con que se lo usa). Juarroz titula toda su obra poesía vertical, y no es dificil comprender su intención. En efecto, la visión que esa obra propone no quiere ser histórica, horizontal, sino en profundidad: confrontación con lo esencial, con lo que de alguna manera ha sido inesencial en la historia y, al parecer, sobre todo en nuestra época. Esa visión explora, sin embargo, en lo más cotidiano del hombre: las cosas que lo rodean y su existencia, el amor, el olvido, la soledad, la nostalgia, el sufrimiento, la muerte. Se podrian escribir estas palabras - sus temas aparentes- en mayúsculas, pero no para sugerir ninguna abstracción vacía (como cuando se habla de los "temas eternos" de la poesía), sino su exacta elementalidad. Lo cotidiano en esta obra, sin dejar de serlo, es igualmente original, primordial. Es, además, sagrado. "Toda palabra nombra a dios", dice Juarroz en su primer libro (Poesia evertical, 1958); "la tarde se convierte en un dios", rei- 
tera en el último (Tercera poesía vertical, 1965). Pero el universo de Juarroz no admite un centro (menos cuando éste sería "la vulgaridad de un Dios cualquiera"); no hay uno sino múltiples centros: cada ser y objeto en el mundo lo es. Centros múltiples, lo importante es aprehender sus relaciones, contrastes y oposiciones. Tales oposiciones son las que generan el impulso de esta poesía: búsqueda de una unidad, que no es una sintesis sino apenas una sierte de tercera dimensión, un fondo que se resuelve en un más allá del fondo, una otra orilla otra. Ese otro lado es indefinible, sólo podemos presentirlo, vivirlo. Digamos, simplificando, que es el lugar donde todo se resuclve en su negación y a partir de ella vislumbra su afirmación. El pensamiento, para Juarroz, sostiene el mundo ("Pensar es como amar"); no obstante ello, dice en uno de sus primeros poemas: "Soy mi propio sostén y me lo quito. / Contribuyo a tapizar de ausencia todo", aludiendo a su propio pensar. En otro texto posterior, afirma: "Sólo el piso de mi pieza me sostiene en el mundo / y reedita la más antigua historia: / una ausencia que sostiene la presencia de otra ausencia" (Segunda poesia vertical, 1963). Este sentimiento de no estar en nada ("en alguna parte sobramos"), de total desasimiento ("Nos duele la forma más íntima del tiempo: / el secreto de no amar lo que amamos") y aun la vivencia de la continua destrucción por la muerte, constituyen, por supuesto, la experiencia del abismo, del no-ser, pero, de algún modo, es el impulso hacia otra manera de ser. La otredad esencial del hombre, el saberse otro, inicia otro movimiento: desconocerse es comenzar a conocerse; la soledad, una forma de comunión; el vacio, de plenitud. Por ello, el verdadero centro para Juarroz es "una ausencia, / de punto, de infinito y aun de ausencia / y sólo se le acierta con ausencia". De ahí que su lenguaje sea también esa ausencia ("el sonido con que suena la soledad en la soledad"), o un sistema de signos contrarios ("la palabra que escribo / escribe otra palabra del otro lado del papel"), o más precisamente una imposibilidad ("la palabra no es sustancia comunicable"). Así, si el lenguaje es conquista, "es la conquista del cero, / la irradiación del punto sin residuo, / el mito de la nada en la palabra". El lenguaje, en definitiva, sería silencio: total despojamiento y desnudez en que, sin embargo, otra palabra habla. "La desnudez - dice Juarroz- es anterior al cuerpo. / Y el cuerpo algunas veces lo recuerda". Su poesía no contiene casi metáforas (trabaja, más bien, con alusiones, aforismos y una "lógica" iluminadora aún en su hermetismo), pero es ella misma una gran metáfora: su propia estructura hace sensible la reflexión que contiene; es el poema "fáit de rien", de que habla Perse. Lo que quiere Juarroz es que el lenguaje, a través de su ausencia, reencuentre otra presencia: la 
elementalidad y la originalidad de las cosas en el mundo; que tenga "la mirada pura de la tierra", "la secreta nitidez de las cosas". Lo que él afirma, finalmente, es ese mundo como la verdadera unidad ("lo único uno", "Evangelio concreto") : la materia fiel a sí misma y no degradada por la historia, aunque está en el tiempo ("encuentro del tiempo con el tiempo", "duración duración"). ¿Habría que decirlo? Esta obra nada tiene que ver con la llamada "poesía pura"; recuerda, más bien, l'écriture blanche de que habla Barthes. Su ascetismo es crítica a la historia, comunión con lo criginal y vislumbramiento de un nuevo goce de la palabra

Aunque sus búsquedas puedan ser distintas, también en algunos poetas de las nuevas generaciones se percibe este doble movimiento: la poesía es simultáneamente una exigencia extrema y una imposibilidad. La poesía es también cuestionamiento que se vuelve sobre si misma. Asi, a la idea de Borges sobre la imposibilidad de escribir un libro, podría corresponder ésta de Heberto Padilla: "Imposible, Drumond, componer un poema a esta altura de la civilización. / El último trovador murió en 1914" (Fuera del juego, 1969). El ejemplo de Padilla es revelador porque su experiencia introduce un nuevo elemento en este debate: la historia concreta. Su obra nace de esa experiencia, pero sobre todo contra ella. Si bien su primer libro (El justo tiempo bumano, 1962) contiene textos que traslucen la esperanza frente a la Revolución que comienza, y hasta una suerte de ascesis en ella, la verdad es que ese libro está dominado por una mirada desencintada de nuestra época. En un poema sobre Blake (no olvidemos: el visionario y el rebelde), Padilla define la naturaleza de nuestro siglo: "Es esa trampa en que luchamos, es esa lluvia / que nos ciega". Y agrega: "Contra mí testifica un inspector de herejias". Tal visión es la que prefigura la de su último libro (Fuera del juego). En este libro, la trampa y el acoso se proyectan tácitamente como símbolos de la realidad y el destino del hombre actual. "La Historia es ese sitio que nos afirma y nos desgarta. / La Historia es esa rata que cada noche sube la escalera", dice muy explícitamente también. En vano quien habla en él intenta oponer su propio marginamiento: se sabe "fatalmente condenado a su época" y a ser su testigo ("está obligado el ojo a ver, a ver, a ver"). Pero este testigo resultará intolerable: no es "optimista", ni "atildado, comedido, obediente", como exige la nueva sociedad. Es, más bien, el gran inconforme. ¿Acaso también el gran iluso? Si no se hace ilusiones con respecto a su libertad, al menós aspira a ejercerla (escribir "poemas sin ataduras"). Busca rescatar un orden personal incontaminado; su "secre.

I Un tratamiento similar del lenguaje, aunque con un sentido más "construc. tor", lo encontramos en Alfredo Silva Estrada, Acercamientos (1969). 
ta y casi desesperante obsesión", dice, es encontrar a alguien capaz de afrontar a salvo la historia. De igual modo, es el desmistificador. Sartrianamente, vuelve a plantear el problema de los medios y los fines, y así descubre el antiguo drama nuevamente repetido: los medios que degradan el fin, la víctima convertida en verdugo, el destino de la Revolución dependiendo de un azar irreparable ("Nosotros somos / el proyecto de Marx, el hedor de los grandes cadáveres / que se pudrian a la orilla del Neva / para que un dirigente acierte o se equivoque"). Pero, para Padilla, estas repeticiones y aun el azar parecen formar parte de una trama más amplia e implacable: la historia misma. La violencia y la deshu. manización, además, parecen estar ligadas a todo poder ("Es difícil construir un imperio / cuando se anhela toda la inocencia del mundo"). Sólo cobrando conciencia de esa fatalidad se la podría trascender. De ahí que su mirada crítica sea igualmente una visión; propone un advenimiento: el nacimiento del justo tiempo bumano, un orden realmente libre y no omnipotente, la final reconciliación de la historia con la inocencia. En otras palabras, propone la verdadera utopía revolucionaria: no sólo corregir la historia, sino liberarse de ella. Así, pues, la actitud de Padilla es crítica, herética y utópica. Postula lo imposible, pero tiene que debatirse en la trampa de una realidad acechante. La claridad de su lenguaje ("Fue más directo que un objeto", dice de sí mismo) es un arma: reactivo que deja descubierta al vivo toda retórica pública; por ello admite también la parodia y el sarcasmo. Pero no por eso la naturaleza de su poesía es menos compleja; fuera y dentro de muchos juegos: doblemente anacrónica, según el tiempo absoluto de la poesía y el progresivo de la historia; do. blemente actual, según el tiempo crítico de la poesía y el mítico o utópico de la historia. De ahí que sea una poesía enfrentada a su propio impase, condenada a postergarse. Un poema titulado "Homenaje a Huidobro" podría ser visto como una suerte de "arte poética" (¿de la resignación?): "No pudimos hacerla florecer en el poema / y la dejamos en el jar. dín, / que es su lugar natural".

"Envejezco al margen de mi tiempo... / porque no puedo comprender exactamente / la historia", dice, por su parte, Enrique Lihn en su último libro (La musiquilla de las pobres esferas, 1969). Este libro es el resumen, no la solución, del debate que domina toda su obra anterior: una subjetividad problemática que quiere liberarse de sus propios fantasmas, aun de sus mitos, a través de la historia y la acción sobre la realidad, pero descubre que éstas son también formas del laberinto del hombre. Aun este proceso no parece tan nítido: Lihn vive la fascinación de lo que intenta liberarse; siente en el pasado, en una infancia que en él no deja 
de ser dramática, la prefiguración de todo su destino ("Todo lo que vivimos lo vivimos / ya a los diez años intensamente"). Su experiencia será, pues, en gran medida circular; la única salida, la catástrofe y la intensidad vertiginosa que suscita: "No hay tiempo que perder en este mundo / embellecido por su fin tan próximo" (La pieza oscura, 1963). Así, este ser dividido va a cuestionar lo que es más esencial en él: la poesía misma. Lihn escribe una poesía con "mala conciencia" porque intuye que el lenguaje nunca alcanza a ser la verdadera ruptura: el paso a otro mundo que de alguna manera sea el absoluto que busca. Es esa intuición la que, casi desde sus comienzos, lo hace sentirse al margen de la literatura. "No hemos nacido para el canto sino para / el acopio de las palabras en ef rechinar de los dientes", dice en un poema dedicado, significativamente, a un poeta suicida de su generación. En ese mismo poema, anuncia incluso que "la poesía ha muerto"; fue su sueño, agrega, difícil de conciliar con los otros: palabras, palabras y en el fondo / sigue a la exaltación un cansancio profundo,/ sólo una rabia negra que tiende a confundirse/ con la oscuridad". Cansancio de la palabra, imposibilidad también de traducir radicalmente la imposibilidad misma de vivir (leyendo a Michaux, siente otra insuficiencia: "un dolor, otra vez, incalculable / para el cual las palabras no tienen gusto a nada"). Progresivamente, va a experimentar el equívoco de su propio sufrimiento expresado en el poema, y así sobreviene, no la ironía, sino el autosarcasmo: "es por una deformación profesional que me permito / este falso aullido" (Poesía de paso, 1966). Lo que menos podía aceptar: el oficio convertido en simple convención, además calculada. La imagen que mejor definirá al poeta será, entonces, la del "bufón", la de "un viejo actor de provincia" que se esmera en llenar el vacío de su voz, sin llegar a comprender nunca el drama que representa. Parece obvio: en Lihn se da muy agudamente la conciencia de lo que Barthes llama "la fatalidad del signo literario": el escritor no puede trazar el menor signo sin tomar la manera o la pose peculiar de un lenguaje ya hecho, convencional. De este modo, su poesía engendra en sí misma su propio enemigo: una conciencia que se autodevora y rehuyendo todo drama no puede evitar caer en el patetismo de expresarlo. El último libro de Lihn es sobre todo crítica, crítica cuyo centro son los mitos de la propia poesía: la magia, la alquimia verbal, el absoluto. La nostalgia del otro Rimbaud lo domina: el no radical, el rechazo, el definitivo mutismo; o el regreso a "la rugosa realidad", a la tierra, la poesía como "instrumento" de la historia ("nosotros estamos, simplemente, ligados a la / historia", dice Lihn). Pero la aparente afirmación de ese regreso es nuevamente ambigua: "un sí de siempre a la siempre 
/ decepcionante evidencia de lo que es / y que las palabras rasguñan, y eso / lo poetizo también". De nuevo, "la mala conciencia" no lo aban. dona: seguirá escribiendo, no callará, pero habla desde lo que de alguna: manera otros prefieren callar: la culpabilidad, la impotencia de la poesía. Sin embargo, finalmente, la poesía es para Lihn una energía ("la ilusión de tener el mundo entre las manos"), una ética ("porque escribí" no estuve en casa del verdugo") y, sobre todo, una razón existencial" ("Porque escribí y me muero por mi cuenta,/ porque escribí porque. escribí estoy vivo").

En otros poetas de las nuevas generaciones, la experiencia de la his. toria y la experiencia poética también se enfrentan, aunque, creo, no para oponerse radicalmente entre sí. Ese enfrentamiento suscita, no obstante, una tendencia que supera a la tradicional poesía social (¿no resultaba ésta: demasiado convencional en el fondo?): no sólo desaparece cualquier maniqueísmo simplista; la rebelión o la crítica nacen ahora desde el lenguaje mismo. En efecto, el lenguaje se convierte en un arma, es, más bien, un contra-lenguaje: en él se insertan todos los materiales "depreciados" por la antigua conciencia (y no sólo estéticamente) valorativa. En ese contralenguaje domina no sólo ya lo narrativo, lo oral y lo prosaico, sino, sobretodo, el material en bruto, el catálogo, el inventario. Es verdad que no. se reduce a ello tan sólo. Ernesto Cardenal, uno de sus iniciadores, tam. bién es capaz del tono lírico (un tanto sentimental a veces) y de cierta. dimensión mística. Peto en un poeta más joven como Antonio Cisneros: (Comentarios reales, 1964; Canto ceremonial contra un oso bormiguero, 1968) alcanza otra experiencia e incluso una nueva pureza: la "narración" gira en torno a ejes múltiples y simultáneos, la crítica se vuelveironía desenfadada y epigramática, quizá, por ello mismo, más eficaz. En esta tendencia, sin embargo, no hay un verdadero impase frente al lenguaje.

No es el caso de José Emilio Pacheco. Su crítica a la historia puede no ser absoluta, sino relativa: corresponde a un mundo que se derrumba inexorablemente ("Pertenezco a una era fugitiva, mundo que se desploma. ante mis ojos"); pero su crítica a la poesía, como veremos, es mucho más. profunda. Lo absoluto en Pacheco es el tiempo: su continua fugacidad que es sobre todo transformación. Lo absoluto es el movimiento y aun la vertiginosidad de los cambios, que se inscriben, por supuesto, dentro. de un finalismo. "Orbe que existe porque cambia y se trasmuta", dice en su último libro (No me preguntes cómo pasa el tiempo, 1969). Esas. mutaciones abren "otra historia", proponen una "página blanca" en la que, al fin, todo será posible. Pacheco, sin embargo, desecha, y aun abo- 
rrece, toda actitud profética; su actitud es, más bien, la de un cronista que mira con cólera impasible y casi impersonal la caída inevitable: en él habla no tanto la fatalidad de la historia como la del tiempo mismo. Pero esa actitud no deja de ser irónica: en él habla también, y sobre todo, la voz del poeta, el que sólo buscó en códices e infolios "el rumor transitivo de las generaciones" o "la pesadumbre de la historia", el que rehuyó la lucha "por asco a vivir de la carroña y la sangre de sus semejantes"; esa voz es la del marginado. Así, se establece un debate entre el advenimiento de un mundo y la incapacidad para asumirlo: participación y soledad. Además, si el tiempo es un absoluto lo es porque lo relativiza todo: la pasión por el tiempo es pasión por lo efímero. Si Pacheco se ve dominado por esa pasión (aun consumiéndose en ella), no la puede expresar sino desde una carencia: la de la propia poesía. Esta es ya doblemente anacrónica: rechazada por la sociedad actual (es "una enfermedad de la conciencia", "un rezago de tiempos anteriores") y también, quizá, por la que se gesta, por la otra historia ("Escribe lo que quieras./ Di lo que se te antoje./ De todas formas / vas a ser condenado). La poesía es, pues, inútil (el precio que se paga "por no saber vivir"); no cambiará la vida y todos sus poderes mágicos no equivalen a los de la historia que nace. "Seres entre dos aguas, marginales de ayer y mañana", son los poetas; nuestra época los "dejó hablando solos". Por su parte, si el lenguaje es movimiento lo es, contrariamente al de la historia, hacia atrás: las palabras cambian vertiginosamente de intención o de significado a medida que el pocta las escribe, pero para ser "dóciles al Carbono 14". Un lenguaje fósil. Escribir resulta, entonces, un acto cùlpable y una condenación: sin esperanza, el poeta sigue "puliendo, desgastando/ un idioma ya seco". Al borde del silencio, la poesía de Pacheco propone, no obstante, otro lenguaje: una palabra viva en un tiempo también vivo de la historia. De ahí quizá que su escritura misma no sea explosiva; está dominada por un desdén irónico, por audacias que son, más bien, irreverencias a las supersticiones cstilísticas o de "vanguardia". De igual modo, su despojamiento intenso es una suerte de pasión o de búsqueda de la nueva palabra. Crítica a la poesía que no excluye la complicidad con ella.

La experiencia de la historia puede admitir también formas más intimas y existenciales: Ia alienación del individuo en la sociedad moderna. Toda la obra de Carlos Germán Belli (reunida en El pie sobre el cuello, 1967) nace de esa desgarradura. Fue justamente un poeta peruano el primero quizá en encarnar este tema en la poesía latinoamericana. Me refiero a César Vallejo, de quien Belli es el continuador legítimo, no simplemente el'epígono. En muchos sentidos, ciertamente, su poesía se acerca à la de 
Vallejo, aunque también se distancia de ella. Como Vallejo, Belli vive en el mundo con el dramatismo (aun masoquista) y la lucidez de la víctima, del humillado: padece y critica, o mejor: su padecimiento es ya crítica, escándalo. También en el lenguaje hay semejanzas: no sólo porque la influencia de Vallejo es asumida deliberadamente en muchos de sus giros característicos (arcaísmos, enclíticos, ponderativos invertidos); igual. mente por la naturaleza de ambos lenguajes: antiguo y actual a la vez. Pero algo profundo los separa: no sólo por el humor negro, que en Belli rs más intenso a la vez que lúcido; además, porque él vive la alienación sin la esperanza utópica que domina finalmente en Vallejo. En efecto, su poesía no postula un futuro: vive de la obsesión de lo que lo rodea; la ética del sufrimiento se convierte en una intencional descripción de lo deforme, lo grotesco, lo absurdo, lo mecánico (su musa es el "hada ciber. nética"). Es, además, el poeta escamecido por la burla ("en un horno yazgo no de cal,/ sino de burla humana"; "los crueles amos blancos del Perú, / mirándome burlonamente siempre"). Frente a ello, por contraste, se siente a un espíritu lúdico (la burla ejercida ahora por el poeta) que experimenta con el lenguaje. Si se asemeja al de Vallejo, como ya hemos indicado, no por ello se diferencia menos. El lenguaje de Belli es un injerto (ni collage, ni bricollage), fusión de dos lenguajes que mutuamente sirven de contextos entre sí: el estilo noble (sintaxis, léxico, mitología) de una poesía clásica o neoclásica, y el estilo oral moderno, con sus giros violentos, refranes callejeros, sintaxis balbuceante, chistes, además de cierto letrismo y figuras oníricas. Temáticamente, incluso, el propio Belli pone énfasis en ese injerto como plagio ("a los sedientos plagios destinado", dice). Lo que es, por supuesto, irónico: el formulismo de una sociedad estratificada y solemne desenmascarado a través de "fórmulas" del lenguaje mismo. Ello tiene, además, otros propósitos: duplicación por el estilo de la realidad peruana (arcaica y moderna a la vez) y también de la realidad más ambigua del mundo (lo angélico enfrentado a la ferocidad). De igual modo, sugiere la despersonalización del autor y de la escritura misma; esa despersonalización ya no es reflejo de ningún enajenamiento, sino, más bien, la busca de una realidad humana inconta. minada, el yo en comunión con el universo. Así, la poesía de Belli, sin ser una reflexión explícita sobre el lenguaje, lo es muy eficazmente a través de una técnica que, en sí misma, es la ruina de los principios en que se funda el lenguaje tradicional: la coherencia de la expresión, la univocidad del signo y del significado. Belli puede ser (¿también la sombra de Borges acá?) un poeta del pasado, pero un poeta del pasado es 
otro a través de Belli. Por debajo del monólogo obsesivo de su obra, se siente, finalmente, el diálogo irónico, la abertura hacia el mundo.

El tema del enajenamiento aparece también en poetas como Juan Sánchez Peláez y Rafael Cadenas. La poesía del primero (reunida, hasta ahora, en Un día sea, 1969) oscila entre la fulguración del deseo y el sigiloso rescate de la infancia, por una parte; y la obsesión del desarraigo o el desamparo en el mundo, por la otra. Progresivamente, ese desarraigo se va haciendo más profundo: es la realidad (visible e invisible) la que le arrebata su otro destino. $Y$ aun cuando el mundo tienda a desaparecer o a ser abolido, irrumpe siempre a través de la conciencia, el otro que lo vigila, lo sigue como una sombra cotidiana (es su "animal de costumbre", título de uno de sus libros) y lo devora. Esa dualidad encarna, a su vez, en un doble lenguaje: uno prestigioso y otro seco, dubitativo, aun balbuceante a veces. Este último funciona como contraste y quizá como crítica de aquél. "No quiero hincharme de palabras", "El poeta se ausenta en el árbol de su mudez", dice Sánchez Peláez. Lo mejor tal vez de su poesía está (y lo estará en el futuro) en esta casi proximidad al silencio: el lenguaje como reducción, absotto en otro lenguaje. La poesía de Cadenas es sobre todo un ejercicio (nada idealizante, por cierto) espiritual: debate contra el yo (que para él es el símbolo de la enajenación en el mundo), el fracaso como liberación de toda vanidad, la búsqueda de la inocencia. Por ello su poesía (especialmente Falsas maniobras, 1966) está sometida a una continua lucidez, que, a veces, no deja de ser irónica: debe pasar la prueba de un "pequeño gimnasio" donde dejará de ser absurda (para la sociedad o el mundo). Esa poesía vive, además, en "la nitidez 'del desierto": experiencia ascética que es acceso a otra realidad donde derrota o triunfo ya no tengan sentido, donde el destino sea no detener destino. Así, el lenguaje de Cadenas intenta desvirtuar al lenguaje, neutralizarlo, modificarlo (fracaso dice otra cosa en él), pero también conquistarlo: hacerlo finalmente posible, devolverle su naturaleza original.

Por otra parte, la despersonalización es una de las empresas esenciales de la literatura moderna. Empresa paradójica: la negación de todo estilo se constituye en otro estilo; la ruina del yo da paso a otro yo; sólo que lo otro no se resuelve sino, inversamente, en su continua negación. Por ello, tal empresa exige el humor $y$ la ironía. En César Fernández Moreno (a partir sobre todo de Argentino basta la muerte, 1966) adquiere el tono de una realidad vertiginosa y ubicua a la vez; un yo, además, que es múltiple. Si lo dominante en su lenguaje es la verbosidad y la proliferación de "estilos", ello es, por supuesto, paródico. Ilustra no sólo la verbosidad argentica o latinoamericana, sino también la de la sociedad 
actual; revela igualmente el vacío de la conciencia y en cierto modo la anula; la realidad misma desaparece, se irrealiza pero a través de sus formas más ostensibles y muertas: las fórmulas ("vea señor lo fundamental es llenar el formulario/ aquí los papeles son la realidad"). Este "máximo" lenguaje resulta, pues, un no-lenguaje: expediente del mundo que se convierte en contra expediente de la palabra. De manera semejante, la poesía de Saúl Yurkievich nos da una visión del mundo contemporáneo a través de su fragmentación, mutaciones incesantes, caos semántico, derrumbes y dispersiones. Su poesía está polarizada por ese vértigo colectivo que un perceptor (no una conciencia) va trasmitiendo indiscriminadamente. Acá estamos ya ante las ruinas del lenguaje mismo: frag. mentos de fragmentos de fragmentos. Poemas que son verdaderos flujos verbales: retahílas de palabras (tomadas de los más diversos campos) o palabras que se empastelan, se atraen y rechazan entre si. Esos poemas prodicen un doble efecto: figuran mecanismos verbales puros independizados de la realidad y a la vez la encarnan de manera profunda: en su disolución. Para Yurkievich la poesía es totalidad en el sentido de que deba decirlo todo. Su último libro (Fricciones, 1969) parece ser la radicalidad misma: es incluso crítica a la poesía crítica, una suerte de "revo. lución permanente" en el lenguaje.

Bueno, supongo que ya debo detener este análisis o simple descripción. No he intentado (ni con buen ojo se me ha pedido) hacer un panorama de la poesía latinoamericana actual. Tan sólo he querido explorar, a través de los poetas más disímiles ("anacrónicos" y de "vanguardia") un tema que parece esencial en la literatura moderna (desde Rimbaud y Mallarmé hasta Kafka y Beckett), y aun en este sentido he tenido que limitarme. ${ }^{2}$ Estos poetas tienden a coincidir, por un momento, en un punto: el cuestionamiento que hacen de la escritura misma, la desconfianza ante el lenguaje. Es un tema recurrente y también múltiple; conduce (aun en un solo pceta) al desdén y al orgullo, a la reducción verbal y a su proliferación, al rechazo de la historia y a su afirmación (en busca de "otra historia", o de la liberación de ella). En cualquier caso, la poesía se constituye en blanco de una conciencia crítica: su precariedad es puesta al vivo hasta en la exacerbación de sus poderes.

¿Por qué esta paradoja? ¿Por qué esta poesía comienza por ser una interferencia desde sí misma? A lo largo de nuestra descripción, hemos indicado algunas motivaciones: la fragmentación e incoherencia del mundo moderno; el enajenamiento del hombre en la sociedad; la historia en su

2 Limitación nò sólo por el tema; sino también temporal: me tefiero a obras aparecidas en los últimos años. Fllo explica algunas grandes omisiones. 
doble apocalipsis de destrucción y advenimiento o revelación. Habría quizá que señalar también la naturaleza pesadillesca y contradictoria de la situación contemporánea: una perspectiva planetaria y, no obstante, la desintegración de nuestra visión del mundo; la sociedad de la comunicación que no se resuelve sino en una soledad más radical; la técnica y el progreso material, pero igualmente la regresión espiritual y la miseria más extrema; una libertad ilimitada y en el fondo la represión; el espíritu crítico y también el conformismo. El mundo de las apariencias se ha vuelto, entonces, una realidad continuamente contaminada de irrealidad. Todo está manipulado y enmascarado (el travesti es una de las figuras más actuales). Pero todo se manipula a través del lenguaje: el de la polí. tica es, hoy, una de las formas de la publicidad. De ahí que Paz señale que lo primero que se degrada es el lenguaje (Posdata, 1970). Es evidente: el lenguaje es también creación histórica, social, nuestro instrumento cotidiano. De esta manera la crítica al mundo es una crítica al lenguaje, y empieza por él. La nueva escritura se inicia, como lo propone Barthes, cuando el escritor, a mediados del siglo xIx, experimenta más agudamente el agrietamiento de la conciencia burguesa. El grado cero de la escritura es una ruptura (frente al signo tradicional); es igualmente una transgresión (de todo signo): fundar el mundo en un lenguaje que se postula como otro, el de una nueva utopía. La búsqueda de ese lenguaje ha requerido sucesivos fracasos (los de Rimbaud, Mallarmé), pero sobre ellos, no obstante, se ha levantado la poesia moderna.

Hay tanibién una desconfianza más esencial frente al lenguaje. Es evidente que toda cultura se funda en la palabra; en numerosas cosmogonías la Palabra crea al mundo. ${ }^{3}$ Pero quizá la occidental ha puesto mayor énfasis en ella, como lo recuerda George Steiner (Language and Silence, 1967). El Logos griego y el Verbo del Evangelio han dominado nuestra experiencia de la realidad: todo es decible o puede ser referido a un dictum superior. Otras experiencias, sin embargo, tienden a debilitar esa concepción excesivamente verbal del universo: la mística, que postula el silencio. Hay incluso toda una tradición para la cual nuestras palabras no serían sino reflejos (profanaciones) de la Palabra. El lenguaje se vincularía, así, al mito de la caida; estaria hecho para la confusión, no para el entendimiento, como en la Torre de Babel. Esta tradición ha tenido, de alguna manera, resonancia en la poesía latinoamericana. Borges, por ejemplo, ve en sus palabras la "pobre traducción temporal de una sola palabra". En uno de los primeros libros de Paz (Semillas para un

3 Ver sobre los poderes del lenguaje el ensayo de Angel Rosenblat, "Sentido nágico de la palabra", en La primera visión de América y otros ensayos (1965). 
bimno, 1954), se convierte en tema central. En efecto, Paz intituye una: suerte de edad de oro donde "Sólo había una palabra inmensa y sin revés / Palabra como un sol", a la que sucede, con la historia, su desmembración en fragmentos "que nunca se unirán", en "espejos rotos donde el mundo se mira destrozado".

Cualquiera que sea su origen, sociológico o si se quiere metafísico, la desconfianza frente al lenguaje implica, por supuesto, la tentación del silencio. El poèa debe fijar vértigos y escribir silencios, proponia Rimbaud; sólo que en él el silencio se hace finalmente literal, total renuncia a la palabra. Esta renuncia resulta de una exigencia más implacable: timar la acción, la palabra como Palabra, encarnación del mundo. El silencio, sin embargo, funciona como una metáfora dentro de un arte que ya es también me'áfora de sí mismo. ${ }^{\star}$ A esa metáfora se llega por diversos: medios y aun persigue diferentes propósitos.

Así, el silencio sería, en primer término, el regreso a las fuentes mismas de la palabra. En efecto, el silencio es inherente al lenguaje: lo que lo hace posible, le da su justeza $\mathrm{y}$, a la vez, denuncia su falsificación. "El silencio esencial es el que está en la palabra misma como su residencia, como su morada; es el silencio que, dicho, entredicho, visto, entrevisto, constituye nuestro hablar esencial", escribe Ramón Xirau (Palabra $y$ silencio, 1968). En un poema de Gonzalo Rojas el silencio no es simplemente meditación en la que se gesta la obra ("Chaque atome de silence / Est la chance d'un fruit mûr", decía Valéry); es también reencuentro. con la energía creadora del mundo, comunión erótica y cósmica: "estás y no estás y casi eres mi Dios/ y casi eres mi padre cuando estoy oscuro" (Contra la muerte, 1964). Ese regreso o reencuentro sería, de igual modo, una purificación. "Donner un sens plus pur aux mots de la tribu", proponía Mallarmé como la misión del poeia. No se trata, como algunos suelen pensar (¿no se habla todavía, y con qué furor de ser revolucionario, de Mallarmé como un poeta de salón?), de buscar quintaesencias, un lenguaje alquitarado, una belleza refinada. ${ }^{5}$ El sentido es, creo, restituirle al lenguaje cotidiano ("aux mots de la tribu") su elementalidad naciente: "le vierge, le vivace et le bel aujourd'hui" de la palabra. Se trata de deslastrarlo de las escorias que lo petrifican; encontrar "un alfabeto con menos historia", dice Juarroz.

El poeta habla sobre el silencio desde el silencio. El silencio es lenguaje, no simple mutismo o mero callarse; presencia de la palabra, no su.

- Ver Susan Sontag, Styles of radical will (1969).

- Ver Jean-Pierte Richard, L'univers imaginaire de Mallatmé (1962), donde se revela la elenentalidad de la visión mallarmeana. 
ausencia. Es quizá en la obra de Homero Aridjis (especialmente en sus dos últimos libros: Los espacios azules, 1968; Ajedrez/Navegaciones, 1969) donde esta experiencia alcanza una más alta expresión. Para Aridjis, la palabra es mundo: portadora de las cosas del universo, lo que invoca, domina y junta; pero esa palabra "sopla desde el fondo del agua / silenciosa / sube de todas partes / quema y nombra". Nombra, sólo que su nombrar "no revela ni oculta": quiere ser el mundo mismo. Por ello también la palabra se identifica con la mirada: "ver es nacer / y al mirar has nacido a la tierra / y tu mirada la ha hecho su reino"; en el amor, la mirada es la iluminación y es igualmente un decir: "lleva tus ojos la palabra". A su vez, el silencio es el ámbito donde reside la palabra y en él sólo puede penetrar la mirada: "él tenía un cuarto de silencio Sin techo ni suelo ni paredes al que sólo su mirada entraba pues su pensamiento en él hacía demasiado ruido". ${ }^{6}$ Es significativa esta proximidad de silencio y mirada. En efecto, la mirada en Aridjis es a stare, como diría Susan Sontag, esto es: una concentración, una fijeza que se vuelve visión ("los ojos son videntes"); no simplemente a look: la pura movilidad superficial del mirar. "Traditional art invites a look. Art that is silent engenders a stare... A stare is perhaps as far from history, as "close to eternity, as contemporary art cant get". Lo que ve Aridjis es un mundo que es nuestro mundo real, pero también su encarnación primordial: una naturaleza mítica a la que se tiene acceso por los sentidos y el ascetismo, por la reconciliación de todo. Así como en su poesía lenguaje y silencio son lo mismo, en el mundo que figura cuerpo y alma lo son también. De ahí que se exalte tanto lo corpóreo ("amo esta corporeidad $/$ esta abertura a mil soles y sombras", "hay un cuerpo en el cuerpo que es el cuerpo de todo") : la materia es sagrada y consagrada por una suerte de presencia cósmica, una divinidad que es espacio reencontrado. Aridjis asume ese espacio: descubre en él lo vivo, la energía, la pureza de todo reino tocado por la inocencia ("he visto el pájaro de la inocencia detenerse"). Sus poemas parecen cumplir la exigencia de Cummings: "live the magnificent honesty of space". Así, su poética podría resumirse en esta frase: "el único milagro es el de la Creación lo demás es anécdota". Lo demás, añadiríamos, es la historia como sucesiva degradación de toda intensidad. Por ello, su obra vislumbra ( $\mathrm{y}$ vive) otro tiempo: comunión con el universo (mujer, fruto, espacio, animalia viva), es también expectación, absorto silencio, "pues uno no sabe por dónde va a brotar la aparición" (por donde va a brotar lo absurdo, replicaría Pa-

- Las blancos de esta cita no son sino un vago ejemplo de cómo el espacio en la página tiené un sentido significativo en los dos últimos libros de Aridjis. 
rra). Y lo que ella finalmente propone no es menos desafiante en aues. tra época: existir. "Lo que nos hace efímeros es nuestra inexistencia,/ si existiéramos no seríamos mortales".

El silencio como metáfora funciona también como duda $y$, más propiamente, como crítica al lenguaje, que es, por supuesto, crítica al mundo. Nunca como ahora, se ha dicho, hemos tenido tantas palabras $y$, sin embargo, nos faltan las palabras. Si el equívoco es el signo de nuestra época, éste parece engendrarse en la proliferación verbal: enmascaramiento de lo real a través de la inflación del lenguaje. Así, claro, se le pro. longa aún más: si ya nadie se fía en las "palabras", muy pocos son los que se curan de la "palabreria". De ahi que a la duda tradicional, más o menos irónica, frente al lenguaje (Words, words, words") ha sucedido ahora la ferocidad ("chillen putas", "hazlas, poeta, haz que se traguen todas sus palabras"). Desde esta perspectiva, la poesía crítica adopta diversas vías. Se constituye en parodia: para mostrar lo irrisorio de aquella opulencia lingüística cultiva la verbosidad como farsa, acumula todos los "estilos" orales posibles, extrae "ready made" del contexto de la falsificación social, como en Fernández Moreno, Yurkievich; Gerardo Deniz (Adrede, 1970) no se ahorra, incluso, en un gran juego de máscaras, la sátira a la literatura misma como institución y vacio ritual, asi como su deliberada demolición. Puede, por otra parte, practicar lo absurdo, lo grotesco y el disparate, como en Parra, en Belli. También, buscar, ajena a toda semántica o propiciando una nueva, la corporeidad visual de las palabras $y$ aun de fragmentos (silabas, letras) de palabras, como en la poesia concreta de Haroldo y Augusto de Campos, o en el Paz de los Toponemas "1968." O, dentro de una línea parecida, proponer la absoluta literalidad (sin más referencia que a sí misma) a través de articulaciones textuales donde el autor es un Autor o muchos, o ninguno, como las que realiza Basilia Papastamatíu (El pensamiento común, 1965). O tender a la total aliteralidad (las palabras ya no son sino sonidos, o ruidos) en una suerte de esperanto poético y nuevo letrismo (lo que obvia, y no es su menor mérito, todo problema de traducción), como el de Rafael José Muñoz en suma poética, El círculo de los 3 soles, 1968 ("Otnatolrop ermad sobre la cusi del diema"). En resumen: el lenguaje como un precipitado explosivo.

El silencio tiene otra faz: fascinación por el lenguaje, búsqueda de 1a Palabra. Esa fascinación, por supuesto, está muy lejos de la verbosidad; implica, sí, la exaltación de lo verbal: reconquista de la energía original del lenguaje (la desaparición del poeta y la iniciativa de las palabras, sugería Mallarmé). Ella supone la nastalgia por lo perdido, pero es tam. 
bién confrontaciỏn con una actualidad, y su crítica. En tal sentido, aunque de distintas maneras, aparece en Borges, Paz y Juarroz. Aparece, igualmente, en poetas de generaciones posteriores. Para Alvaro Muti (Los elementos del desastre, 1953; Los trabajos perdidos, 1965), la poesía a un tiempo inútil e imposible; si su misión es nombrar la realidad, las palabras están demás; si propone un advenimiento, entonces faltan: sólo los dioses harían el poema, "no hay hombres para esta faena". Las palabras son máscara y no revelación: "nos cubren de tal modo que nos perdemos lo mejor de la batalla". Así, la poesía es sólo un sucedáneo; substituye, no encarna el mundo. Sin embargo, la obra misma de Mutis (desencadenamiento y precisión, delirio y lucidez) no propicia sino la aparición de otro lenguaje: "Cuando de repente en mitad de la vida llega una palabra / jamás antes pronunciada, / una densa marea nos recoge en sus brazos y comienza el / largo viaje entre la magia recién nacida". La crítica, pues, se convierte en arrebato de la magia verbal. Esa magia está presente en Olga Orozco (Los juegos peligrosos, 1962), en Luis García Morales (Lo real y la memoria, 1962), en César Dávila Andrade (Materia real, 1969).

Toda la obra de Jorge Teillier, a su vez, se desarrolla como una dialéctica entre la plenitud y la desposesión, que se resuelve en una suerte de ausencia o de nostalgia: insaciablemente, este poeta busca en el pasado, sobre todo en la infancia, la original intensidad de la experiencia, que, sin embargo, ya se ha extinguido. Su lenguaje es la conquista de esa ausencia, y habla desde ella. Pues la verdadera realidad es siempre otra: "todo lo que está aquí / parece estar verdaderamente en otro lugar". Del mismo modo, el verdadero lenguaje es otro o de otro: "nuestros días son palabras que esconden más grandes palabras / pronunciadas por Otro". La conciencia de esta ambivalencia es lo que comunica intensidad a esta poesía esencialmente memoriosa: memoria de la Realidad y, más dramáticamente, memoria de la Palabra. En José Carlos Becerra (Relación de los hechos, 1967), el lenguaje presenta sus dos rostros. Por una parte, "le abre la puerta a una frase cubierta de polvo"; es decir, la historia y la fugacidad del lenguaje, también su $b(v)$ analidad. Por la otra, es la energía ancestral esperada, la revelación del principio: "Cada palabra que llega a mis labios me trae un oscuro mensaje / de aquella, la Palabra desconocida y presentida, que sigo esperando". El debate (inversión, reversión) entre uno y otro lenguaje es lo que sustenta la realidad misma de esta experiencia: en medio de las ruinas (personales y colectivas) del presente, la ardiente nostalgia de lo sagtado y lo mítico, la conciencia del "ailleurs". Así, la relación de los hechos no propone aquí ningứn 
nuevo realismo, aunque tampoco ninguna fabulación. Propone una revelación, una abertura distinta hacia el mundo. "Amanece en medio de mi -dice este poeta- y yo me quedo mirando el otro lado en que no estoy". La visión de Tomás Segovia es todavía más sostenida; el amor, el cuerpo, la experiencia cotidiana o histórica del hombre se integran, en su obra, dentro de un contexto más vasto y resonante: la memoria mítica. Para Segovia, el exilio y la errancia son condiciones esenciales del hombre: sólo el riesgo y el desamparo hacen posible la fundación de la morada. Y es el poeta el que realiza esa fundación; el poeta es el ser ausente-presente, el nómada y el hijo pródigo; el que parte y regresa, pero regresa sobre todo a través de su memoria. La poesía sería, entonces, un continuo reconocimiento (su mejor libro se titula Anagnórisis, 1967): toda contigencia - histórica o personal-es: remitida al mito, pero todo mito, a su vez, encarna en una contigencia. La verdadera realidad sería, pues, perpetua transferencia de lo uno a lo otro, "vasos comunicantes" posibles a través de las palabras y la Palabra.

Si la devaluación del lenguaje está ligada a "la caída" o a la historia, la exaltación del cuerpo como pasión edénica o del mito como tiempo absoluto se constituyen en una conciencia crítica al revés. Quizá sea en la obra de dos poetas mayores, José Lezama Lima y Enrique Molina, donde esta tentativa muestra toda su plenitud. El deslumbramiento en que ambas obras se originan es ya crítica: el lenguaje mismo es cuerpo y placer; la poesía es deseo. Aunque sus caminos sean muy distintos, conducen a ese centro común.

Lezama parte de una ausencia ("El deseoso es el huidizo", "Los deseos cercan el cuerpo en otro cuerpo fugado") que va adquiriendo densidad sólo a través de la imaginación. Esta es una "sustancia adherente" y el poema su sucesiva y copiosa cristalización ("pues sólo la sobreabundancia inunda los rostros y los encarna"). Resultado: un mundo verbal que se libera de toda referencia realista, se independiza y forma un cuerpo cerrado en sí mismo pero también resonante: emblema del universo. Es la irrealidad lo que se vuelve real en Lezama, lo mítico y aun lo deliberadamente anacrónico lo que se hace tiempo, la palabra (y nadie como Lezama tiene y vive el placer de la palabra) lo que impone un absoluto. Ese absoluto es vertiginoso e incesante, no conoce límites; la poesía no es resultado sino movimiento: vive del deseo mismo, no de la posesión. "Sólo el mercader acaricia sus telas y recibe lo esperado", dice Lezama. ¿No estamos, también, ante una ética de la palabra? Lo fundamental del escritor, dice, como resumiendo esa ética, es: "Que maneje fuerzas que lo arrebaten, que parece que van a destruirlo. Que se apodere de ese reto y 
disuelva la resistencia. Que destruya el lenguaje y que cree el lenguaje. Que durante el dia no tenga pasado y por la noche sea milenario".

Enrique Molina, por el contrario, parte de una presencia y está dominado por la pasión ("iRacimo de pasiones! Pon aquí tu sentencia"). Esa pasión lo conduce a la errancia; es el poeta nómade por excelencia: su signo es el mar, el espacio desencadenado y libre ("Yo pertenezco a la intemperie"). Pero su poesía no tiene nada de mural realista o de registro descriptivo, aunque su mirada es siempre precisa; es, más bien, una visión: abertura hacia lo que él llama "la enloquecedora primavera" - "la belleza demoníaca del mundo". Esa visión es, igualmente, una embriaguez, impone la dispersión y el extravio ("Homenaje a una belleza salvaje que exige el desorden"). Así, su impulso erótico (tan intenso como el del Neruda de la primera época) lo abarca todo: la mujer y el universo ("Adora ese sol que nace/De una mujer que se desnuda"), y aunque se enfrente a las destrucciones del tiempo, su destrucción se vuelve una victoria, nueva posesión, a través de la memoria. En ese impulso se reconcilian los opuestos, los "antipodas"; pero es sobre todo la conquista de una naturaleza primitiva, llena de terrores antiguos y de dioses, y de una intensidad que ya creíamos perdida. Su propósito es, justamente, encontrar "una ley furiosa, una ardiente ofensa/al peso de los días". Cuál sería la verdadera justificación del hombre, se pregunta, "sino sobrepujar una costumbre de polvo y tedio". Así, su poesía es el intento por tras. cender todo tiempo y toda historia: hacer de la vida misma un absoluto. Por ello, Molina hace de la existencia y del mundo solar que figura un mito, o mejor: toda presencia está polarizada por la ausencia de lo mítico y lo sagrado, que, por un instante, encarnan en el poema. Si su poesía se nutre, aparentemente, de un deseo realizado, la verdad es que ese deseo, como en Lezama, es insaciable: fijeza y movimiento sin fin. Ese deseo implica una ética de la palabra, no su historia. Su poesía, al igual que la de Lezama, es una poesía anacrónica. Se ha dicho que Molina es un poeta surrealista; si lo es, lo es a la manera en que Breton definía el surrealismo de Perse: "à distance". Nombrado Perse, habría que decir que está más cerca de él: no sólo por la tensión espacial y el tono ponderativo de su lenguaje; también por la capacidad de volver mítica la experiencia en el mundo.

A estas alturas, no deja de invadirme cietto terror. Leo en un joven gran poeta, Marco Antonio Montes de Oca: "No hay silencio que valga la pena de una misa" (Pedir el fuego, 1968). Para un poeta aún más grande como Neruda el silencio equivale a "morir entre los seres" (Plenos poderes, 1962), aunque en uno de sus últimos libros reconoce: "pero 
aprendi tanto silencio/que tengo mucho que callar" (Fin de mundo, 1969). Este último testimonio me reconforta: a pesar de su aprendizaje, Neruda escribe y sigue escribiendo, con su igual e inigualable desmesura. De igual modo, aunque el silencio (o su tentación) es de verdad problemático en la maycría de los poetas que he analizado, éstos se las arreglan para seguir escribiendo. Nada extraño: era el reproche que le hacía Russell a Wittgenstein, quien llenó páginas y páginas sobre la imposibilidad de decir algo. Aún así, espero, con todas mis dudas, no haber transgredido los límites en este artículo. En verdad, no soy yo quien ha hablado, sino los poetas mismos. Pues nada más inútil que la crítica; su único método es la tautologia: repetir lo que ya está en la obra.

University of Pittsburgh

GUILLERMo SUCRE 
